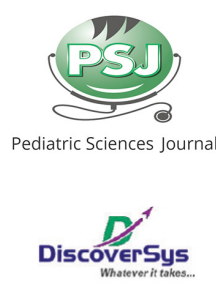

Published by DiscoverSys

\title{
Fecal secretory immunoglobulin a, human $ß$ defensin-2, and calprotectin levels in preterm neonates who consumes breast milk only, formula milk only, and combination
}

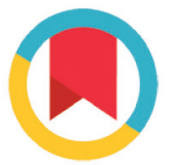

CrossMark

\author{
Eko Sulistijono ${ }^{1 *}$, Putri Primawardani ${ }^{1}$, Rusdian N.Ningsih ${ }^{1}$, Bernardinus P.A.Pradipta ${ }^{1}$
}

\section{ABSTRACT}

Background: Secretory immunoglobulin A, human B-defensin2 and calprotectin play an essential role in digestive system defense. This study aims to assess fecal SIgA, hBD-2, and calprotectin in preterm neonates (as inflammation marker) with different feeding patterns.

Method: This study was cohort designed included 39 preterm neonates, which were categorized into breast milk only, formula milk only, and combination. Fecal SIgA, hBD-2, and calprotectin measured by ELISA.
Results: Fecal Slga in the breast milk only group were significantly higher $(p<0.005)$. Fecal HBD-2 and calprotectin in the formula milk only group were highest but not significantly different $(p=0.463)$ with the combination group.

Conclusion: Fecal SlgA levels that consumed breast milk only were significantly higher. Fecal HBD-2 and calprotectin levels that consumed formula milk only were highest but not significantly different from the combination group.

Keywords: secretory IgA, HBD2, calprotectin, preterm, fecal

Cite this Article: Sulistijono, E., Promawardani, P., Ningsih, R.N., Pradipta, B.P.A. 2020. PFecal secretory immunoglobulin a, human B defensin-2, and calprotectin levels in preterm neonates who consumes breast milk only, formula milk only, and combination. Pediatrics Sciences Journal 1(2) : 57-65.

'Department of Child Health, Faculty of Medicine, Brawijaya University, Saiful Anwar Hospital, Malang, Indonesia

\footnotetext{
*Corresponding to:

Eko Sulistijono; Department of Child Health, Faculty of Medicine, Brawijaya University, Saiful Anwar Hospital, Malang, Indonesia; ekosulistijono@yahoo.com
}

Received: 2020-10-04 Accepted: 2020-12-05 Published: 2020-12-24
The first 28 days of life is the most vulnerable time for a child's survival. Globally, 2.4 million children died in the first month of life in 2019. World Health Organization (WHO) reports that $44 \%$ of child deaths in 2012 occurred during the neonatal period. The situation improved in 2018 by reducing the death rate to 2.5 million but $47 \%$ still occur at neonatal age. Data shows that around 7000 neonatal deaths occur each day where one third dies on the first day of life, and three quarters occur on the first week of life. ${ }^{1,2}$ Prematurity and low birth weight are conditions that increase the risk of death in the neonatal period. ${ }^{3}$

The most common cause of death in neonates is gastrointestinal infections, including necrotizing enterocolitis (NEC). NEC incidence ranges from $1-5 \%$ of every 1000 live births and often occurs in low birth weight (LBW) and low birth weight (VLBW) neonates, mortality rates reaching 20-30\%. During 2009, the perinatology division of Cipto Mangunkusumo Hospital (RSCM) received 31 NEC cases from around 737 premature births. ${ }^{4,5}$

Strategies are needed to increase the life expectancy of preterm neonates, one of which is optimal nutrition through exclusive breastfeeding. Humanbreastmilk(ASI) isassociated with protection against various diseases through complementary and innate defense factors, including IgA secretory antibodies, oligosaccharides and glycoconjugates, and antimicrobial peptides (AMPs). ${ }^{1,6}$ Definitive marker to establish infection in gastrointestinal is quite difficult. Clinical manifestations show relatively similar results with other manifestations origin outside GI tract. ${ }^{7}$ Non-invasive biomarkers that can detect GI inflammation earlier before clinical symptoms are needed to reduce GI infections' morbidity and mortality caused by GI infections. Fecal biomarkers are one of the non-invasive screening options and expected to reflect inflammation and specific digestive tract pathological conditions. ${ }^{8}$

Previous research comparing human milk and formula milk to levels of neonatal fecal secretory immunoglobulin A, human beta-defensin two and calprotectin is still minimal. Therefore, this study aims to determine the levels of neonatal fecal secretory immunoglobulin A, human beta-defensin 2, and calprotectin as biomarkers of GI inflammation in preterm neonates who consume human-only milk, formula milk only, or combination at the age of seven days and fourteen days. 


\section{MATERIAL AND METHOD}

\section{Research design}

This research is prospective analytic using cohort study design conducted in the neonatology ward Dr. Saiful Anwar General Hospital (RSSA) Malang and Physiology Laboratory of Faculty of Medicine, Brawijaya University, Malang November 2019. The RSSA ethics team has approved this research with letter number: 400/244/K.3 /302/2019.

\section{Population and subject}

The study population was preterm neonates (gestational age $<32$ weeks) treated in the RSSA neonatology ward from 15 November 2019 to 15 February 2020. The inclusion criteria were preterm neonates with APGAR score $>5$ at the fifth minute; preterm neonates without congenital abnormalities or gastrointestinal anatomy abnormalities; the history of a mother with a BMI of $18-25 \mathrm{~kg} / \mathrm{m} 2$ before pregnancy; not experiencing chorioamnionitis, which is characterized by; leukocytes more than $20000 / \mathrm{nl}$, temperature more than $38^{\circ} \mathrm{C}$. Exclusion criteria are preterm neonates who were not born at Saiful Anwar Hospital Malang (referral); preterm neonates with small for gestational age or large for gestational age; preterm neonates with endocrine chromosomal abnormalities; the history of mothers with autoimmune diseases and other chronic diseases.

Samples were taken in preterm neonates aged 7 and 14 days. Thirty-nine samples were obtained divided into three groups: consumed breast milk only, breast milk and formula milk, and formula milk.

\section{Stool sample preparation}

Samples were taken from feces on the diaper using a spatula. Transport is placed in a clean tube and delivered in less than 30 minutes using a particular container to maintain a stable temperature.

\section{Calculation of SIgA, HBD-2, and Calprotectin levels}

Levels of SIgA, HBD-2, and stool Calprotectin were measured by enzyme-linked immunosorbent assay (ELISA) method using Human secretory immunoglobulin A ELISA Kit Bioassay Technology Laboratory Cat.No. E01966Hu for SIgA, Human Beta Defensin 2 ELISA Kit Bioassay Technology Laboratory Cat.No. E01936Hu for HBD-2, and Human Calprotectin ELISA Kit Bioassay Technology Laboratory Cat.No. E4010Hu for calprotectin. Levels of fecal SIgA, HBD-2, and calprotectin were measured if the samples had been homogenized and extracted with wash buffer. Wash buffer concentrate preparations (25x) taken $20 \mathrm{~mL}$ are diluted with deionized or distilled water up to $500 \mathrm{~mL}$. A total of $10 \mathrm{~mL}$ wash buffer was added for every $100 \mathrm{mg}$ stool sample (1: 100). Then, shaken using a vortex for 5 minutes, $1 \mathrm{ml}$ of the mixture was added to Eppendorf centrifuged for 20 minutes (2000-3000 RPM) to obtain a supernatant. Extraction results can last for one month when stored at $-20 \mathrm{oC}$. Before being analyzed, a 1:10 supernatant $(100 \mu \mathrm{L}+900 \mu \mathrm{L}$ wash buffer $)$ was diluted for SIgA examination and 1: $100(1 \mu \mathrm{L}$ $+100 \mu \mathrm{L}$ wash buffer) was carried out twice for HBD-2 and calprotectin examination. The standard solution will be calculated with an optical density of each sample's color intensity to determine the concentration of SIgA, HBD-2, and Calprotectin. ELISA results are read after 10 minutes of giving a stop solution.

\section{Statistic analysis}

Data was collected from measurement results of SIgA, HBD-2, and calprotectin groups that only received breast milk, breast milk and formula milk, and formula milk. Data analysis using normality test, comparative test, and correlation test that processed using SPSS software.

\section{RESULTS}

\section{Sample Characteristics}

The sample's essential characteristics were neonates characteristics (sex, mode of delivery, gestational age, birth weight, length of birth, and head circumference) and mothers characteristics (preeclampsia, eclampsia, history of premature rupture of the membrane, and amused pregnancy). Each characteristic was analyzed using chi-square with a p-value $>0.05$, which means there were no significant differences between them (Tabel 1).

\section{Levels of fecal Secretory Immunoglobulin A, Human Beta Defensin 2, and Calprotectin}

SIgA levels were described in $\mu \mathrm{g} / \mathrm{ml}$, where the highest value was obtained in the preterm neonatal group at fourteen days of age who consumed human breast milk only at $2091 \mu \mathrm{g} / \mathrm{ml}$, and the lowest value was obtained in the formula milk only $(194.77 \mu \mathrm{g} / \mathrm{mL})$. Fecal SIgA levels at the age of seven days $(734.5-1717 \mu \mathrm{g} / \mathrm{mL})$ were lower than those at fourteen days $(835.8-2091.2 \mu \mathrm{g} / \mathrm{mL})$ in preterm neonates who consumed human breast milk only. Whereas in the group who consumed breast milk and formula milk, fecal SIgA levels on the seventh day $(689-1815.1 \mu \mathrm{g} / \mathrm{mL})$ were higher than the fourteenth day $(453.78-11603 \mu \mathrm{g} / \mathrm{mL})$. Similarly, in the preterm neonate group who consumed formula milk only (seventh day: 328.1-1010 $\mu \mathrm{g} / \mathrm{mL}$, fourteenth day: 194.77-214.11 $11 \mu \mathrm{g} / \mathrm{mL}$ ) (Figure 1) 
Table 1. Basic characteristic of sample

\begin{tabular}{|c|c|c|c|}
\hline Characteristic & $\begin{array}{l}\text { Human breast } \\
\text { milk only }\end{array}$ & $\begin{array}{c}\text { Human breast } \\
\text { milk and formula } \\
\text { milk }\end{array}$ & $\begin{array}{l}\text { Formula } \\
\text { milk only }\end{array}$ \\
\hline \multicolumn{4}{|l|}{ Gender, (n) } \\
\hline - Laki-laki & $6 / 13$ & $4 / 13$ & $4 / 13$ \\
\hline - Perempuan & $7 / 13$ & $9 / 13$ & $9 / 13$ \\
\hline $\begin{array}{l}\text { Gestational age (week), } \\
\text { median (min-max) }\end{array}$ & & $30(25-32)$ & \\
\hline - $<28$ & $2 / 13$ & $1 / 13$ & - \\
\hline - $28-30$ & $4 / 13$ & $6 / 13$ & $5 / 13$ \\
\hline - $30-32$ & $7 / 13$ & $6 / 39$ & $8 / 13$ \\
\hline $\begin{array}{l}\text { Birth weight (grams), } \\
\text { mean (SD) }\end{array}$ & $1553,8( \pm 430,7)$ & $1459,7( \pm 406,5)$ & $1010( \pm 506,4)$ \\
\hline $\begin{array}{l}\text { Birth length, mean (SD) } \\
(\mathrm{cms})\end{array}$ & $39,2( \pm 4,6)$ & $39,5( \pm 2,9)$ & $40,9( \pm 4,0)$ \\
\hline $\begin{array}{l}\text { Head circumference, } \\
\text { mean }(\mathrm{SD})(\mathrm{cms})\end{array}$ & $28,2( \pm 2,1)$ & $27,8( \pm 1,7)$ & $28,4( \pm 1,8)$ \\
\hline Oxygen therapy (n) & $6 / 13$ & $7 / 13$ & $5 / 13$ \\
\hline \multicolumn{4}{|l|}{ Mode of delivery(n) } \\
\hline - Normal & $7 / 13$ & $3 / 13$ & $3 / 13$ \\
\hline - Sectio caesarian & $6 / 13$ & $10 / 13$ & $10 / 13$ \\
\hline \multicolumn{4}{|l|}{ History of pregnancy(n) } \\
\hline - Preeclampsia & $3 / 13$ & $4 / 13$ & $6 / 13$ \\
\hline - Eclampsia & - & - & $1 / 13$ \\
\hline $\begin{array}{l}\text { - Premature ruptured } \\
\text { of the membrane }\end{array}$ & $3 / 13$ & $6 / 13$ & $6 / 13$ \\
\hline - Gemelli & $2 / 13$ & - & - \\
\hline \multicolumn{4}{|l|}{ Clinnical condition (n) } \\
\hline - Respiratory distress & $6 / 13$ & $6 / 13$ & $6 / 13$ \\
\hline - Vomiting & $10 / 13$ & $9 / 13$ & $9 / 13$ \\
\hline - Distended abdomen & $9 / 13$ & $9 / 13$ & $5 / 13$ \\
\hline Antibiotic use (n) & $7 / 13$ & $9 / 13$ & $11 / 13$ \\
\hline
\end{tabular}

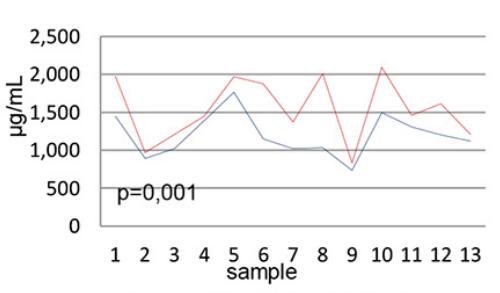

(a) Human breast milk only

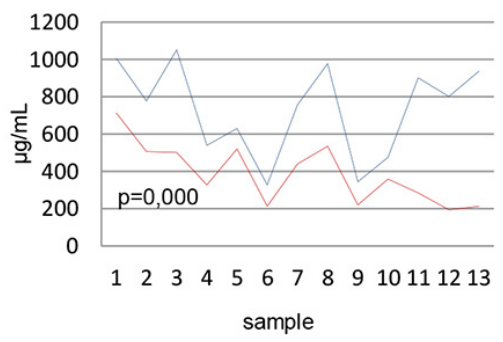

(c) Formula milk only

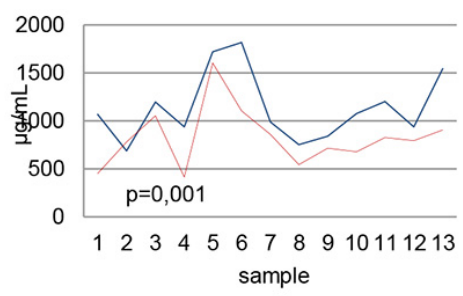

(b) Human breast milk and formula milk

Seventh day

Fourteenth day
Figure 1. Fecal levels of Secretorry immunoglobulin A in preterm neonates who consume human breast milk only, human breast milk and formula milk, and formula milk only on the seventh and fourteenth days
Fecal HBD-2 levels were described in $\mathrm{ng} / \mathrm{mL}$ where the highest values were obtained in the preterm neonate group who consumed formula milk on the fourteenth day $(492 \mathrm{ng} / \mathrm{mL})$, and the lowest values were obtained in the preterm neonatal group aged fourteen days who consumed breast milk only (151.78 ng/mL). Fecal HBD-2 levels at seven days $(158.27-2284.77 \mathrm{ng} / \mathrm{mL})$ were higher than fourteen days (152.77-2249.77 ng/mL). Fecal HBD-2 levels were obtained higher on the fourteenth day $(228.02$ $\mathrm{ng} / \mathrm{mL}$ and $184.52 \mathrm{ng} / \mathrm{mL}$ ) than on the seventh day $(210.27 \mathrm{ng} / \mathrm{mL}$ and $174.52 \mathrm{ng} / \mathrm{mL})$. Whereas in the group who consumed breast milk and formula milk, the levels of fecal HBD-2 on the fourteenth day $(304.27-430.27 \mathrm{ng} / \mathrm{mL})$ were higher than the seventh day (222.77-391.02 ng/mL). Similarly, in the preterm neonate group who consumed formula milk only (seventh day: 230.77-426.77 ng/mL, fourteenth day: 311.22 - $492.27 \mathrm{ng} / \mathrm{mL}$ ) (Figure 2).

Fecal calprotectin levels are described in ng/ $\mathrm{mL}$, where the highest value is obtained in preterm neonates who consume formula milk only on the fourteenth day $(737.28 \mathrm{ng} / \mathrm{mL}$ ), and the lowest value is found in the group of preterm neonates aged fourteen days consuming breast milk only $(103.28 \mathrm{ng} / \mathrm{mL})$. For preterm neonates who consumed breast milk only, fecal calprotectin levels at the age of seven days (103.28-226.28 ng/mL) were higher than those of fourteen days (103.28$2249.77 \mathrm{ng} / \mathrm{mL}$ ). Along with fecal HBD-2 data, two subjects with higher calprotectin levels were found on the fourteenth day $(229.28 \mathrm{ng} / \mathrm{mL}$ and 200.52 $\mathrm{ng} / \mathrm{mL}$ ) compared to the seventh day $(226.29 \mathrm{ng} /$ $\mathrm{mL}$ and $185,02 \mathrm{ng} / \mathrm{mL}$ ). Whereas in the group who consumed breast milk and formula milk, fecal calprotectin levels on the fourteenth day (248.52$498.78 \mathrm{ng} / \mathrm{mL}$ ) were higher than the seventh day $(140.02-2298.78 \mathrm{ng} / \mathrm{mL})$. Likewise, in the group that consumed formula milk only (seventh day: 308.28-500.78 ng/mL, fourteenth day: 358.02$277.75 \mathrm{ng} / \mathrm{mL}$ ) (Figure 3).

Based on the ANOVA test, fecal levels of SIgA calprotectin in each neonate group were significantly different $(p<0.005)$. While the fecal level of HBD-2 in the formula milk the only group was not significantly different from the combination group of breast milk and formula milk ( $\mathrm{p}=0.395)$, although, in the formula milk group, the mean of fecal HBD-2 was higher than the other groups $(349,16 \pm 67,66)$ (Table 2).

Comparative analysis of paired T-tests can be concluded that there are differences in the fecal level of SIgA, HBD-2, and calprotectin in three groups of preterm neonates on the seventh and fourteenth days, which are statistically significant. Human breastfeeding only can increase the average 
levels of fecal SIgA $(1541.9+418.6)$ and reduce the average levels of fecal HBD-2 $(204.47+40.63)$ and calprotectin $(119.97+38.94)$ on the fourteenth day which was statistically significantly different from the seventh day (SIgA p $=0.001$; HBD-2 $\mathrm{p}$ $=0.039$; calprotectin $\mathrm{p}=0.021)$. Meanwhile, the consumption of a combination of breast milk and formula milk and formula milk only decreased the average fecal level SIgA and increased the average fecal levels of HBD-2 and calprotectin on the

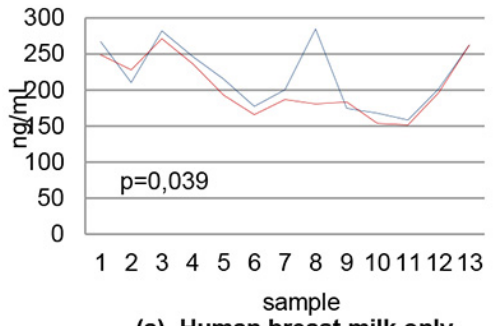

(a) Human breast milk only

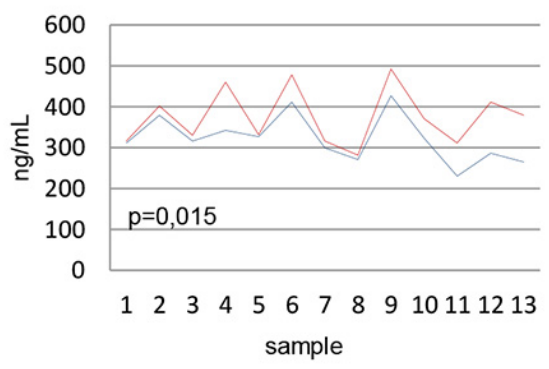

(c) Formula milk only

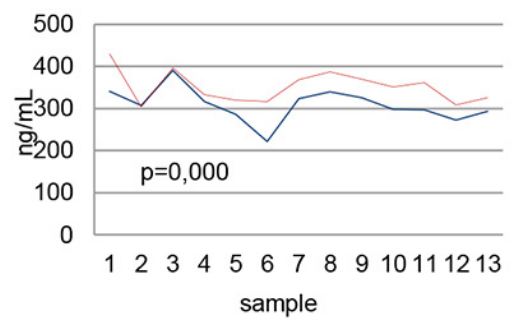

(b) Human breast milk and formula milk

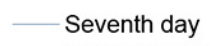

Fourteenth day

Figure 2. Fecal levels of HBD-2 in preterm neonatal who consume human breast milk only, human breast milk and formula milk, and formula milk only on the seventh and fourteenth days.

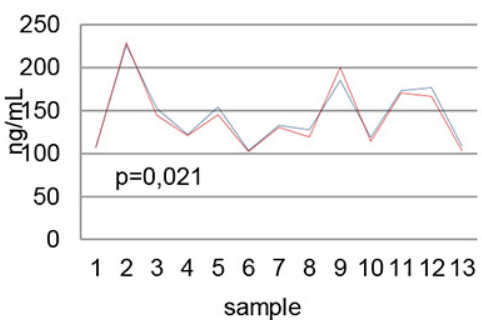

(a) Human breast milk

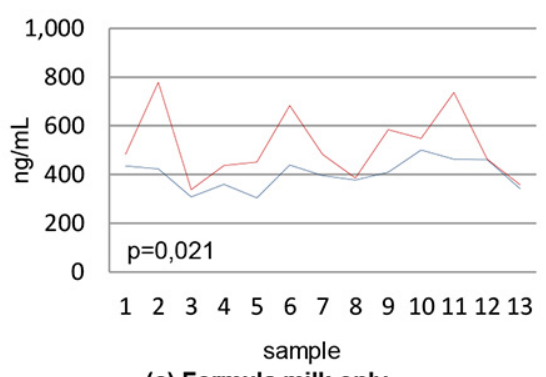

(c) Formula milk only

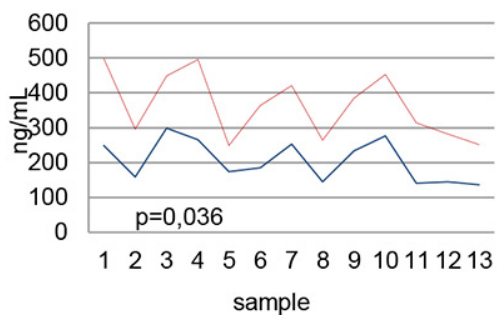

(b) Human breast milk and formula milk

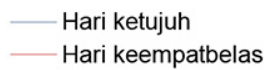

Figure 3. Fecal levels of calprotectin in preterm neonatal who consume human breast milk only, human breast milk and formula milk, and formula milk only on the seventh and fourteenth days. fourteenth day $(\operatorname{SIgA} 0=0.001$ and $\mathrm{p}=0.00$; HBD$2 \mathrm{p}=0.00$ and $\mathrm{p}=0.015 ;$ calprotectin $\mathrm{p}=0.036$ and $\mathrm{p}=0.021)$ which are all significantly significant compared to the seventh day (Table 3 ).

Based on the Bivariate Pearson correlation test, an increase in fecal SIgA levels was strongly associated with decreased HBD-2 and calprotectin level ( $p=0.003$ with $r$ counts: -0.467 and -0.456 ). In comparison, the increase in fecal HBD-2 levels was associated with an increase in fecal calprotectin $(p=0.003$, $r$ count: +0.466$)$. Relationship analysis on the fourteenth day was not much different from the seventh day. An increase in fecal SIgA levels was associated with decreased HBD-2 and calprotectin levels ( $\mathrm{r}$ count -0.789 and -0.805 ). Meanwhile, fecal levels of HBD-2 and calprotectin on the fourteenth day had a significant correlation $(p=0,000)$, which was positive with an $r$ count of 0.769 . The correlation data can be seen in Table 4 .

\section{DISCUSSION}

More than $85 \%$ of gastrointestinal inflammation occurs in neonates with birth weight $<1500$ grams or gestational age $<32$ weeks. Good et al., 2014 proves that preterm birth is a major risk factor for incidence of necrotizing enterocolitis, this illustrates the immature state of gastrointestinal tract in preterm infants. Gastrointestinal immaturity is associated with changes in components of intestinal defense system, lack of mucus production, increased permeability, decreased production of gastric acid and proteolytic enzymes, as well as hormones and digestive enzymes that have not mature yet. ${ }^{10}$

Secretory immunoglobulin A (SIgA) has functions as the first line defense in protecting the gastrointestinal epithelium from enteric toxins and pathogenic microorganisms through a process known as immune exclusion where SIgA initiates clearance of antigen and pathogenic microorganisms from gastrointestinal lumen. ${ }^{11}$ In addition, the secretory component attached to IgA makes SIgA more stable (not easily destroyed by proteolytic enzymes) compared to other immunoglobulins, so that measurement of fecal SIgA levels reflects the competence of gastrointestinal mucosal immune response. Several previous studies have proven that SIgA levels can be detected in fecal specimens, especially neonates who are breastfed in the first week of life. ${ }^{12,13}$

Mean level of fecal SIgA in neonatal group consuming breast milk only $(1307.3 \pm 389.66 \mu \mathrm{g} /$ $\mathrm{mL}$ ) were significantly higher than other two groups. These results are in line with preliminary research where fecal SIgA levels higher in the group consuming breast milk compared to formula milk at 2 weeks, 4 weeks and 8 weeks. ${ }^{14}$ Kuitunen 
\& Savilahti, 2015 explained that fecal SIgA levels in neonates who consumed breast milk were 3-9 times higher than those who consumed formula milk only. ${ }^{15}$ Likewise Maruyama et al., 2009 and Bridgman et al., 2016 which proved the level of fecal SIgA in neonates who consumed breast milk only was higher than neonates who consumed formula milk. ${ }^{13,16}$

Table 2. Comparative test results of immunoglobulin A, HBD-2, and preterm neonatal fecal calprotectin levels

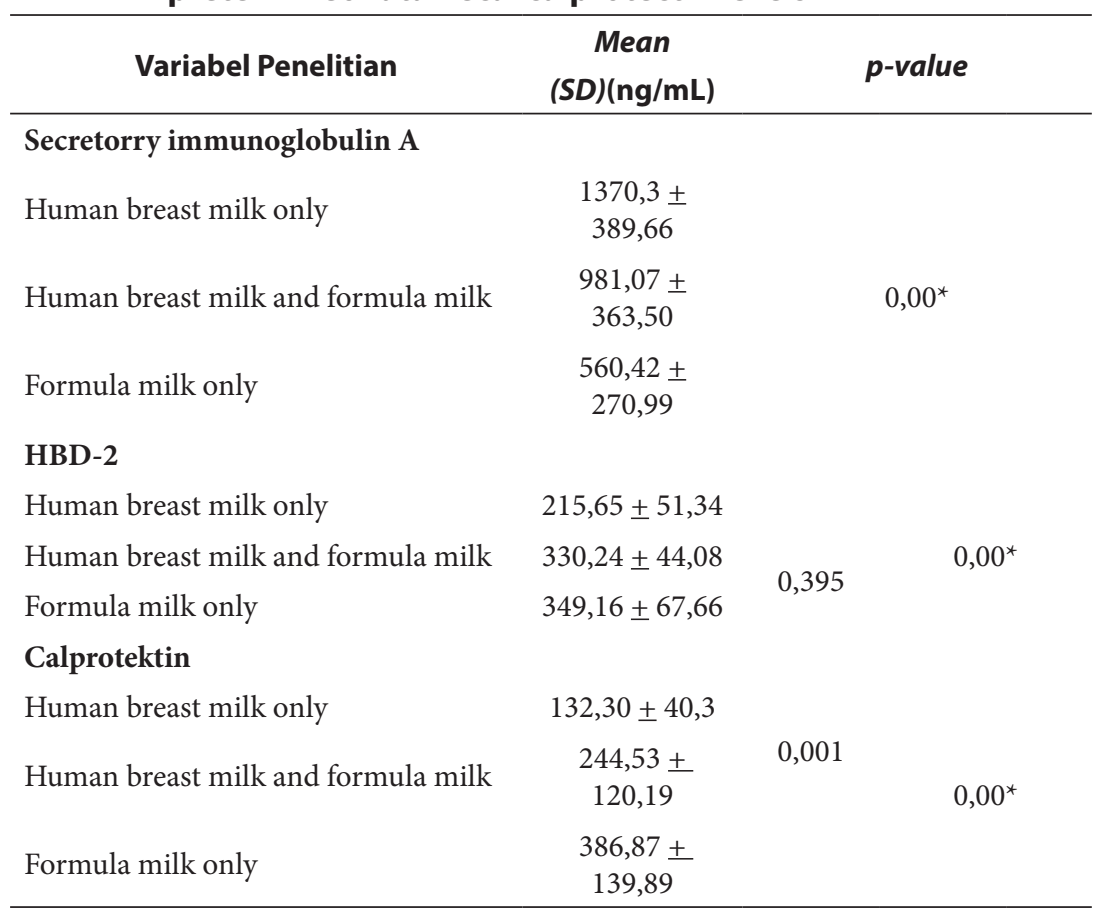

Note: $\mathrm{p}$-value $<0.05=$ significant $\left({ }^{*}\right)$
The study was conducted in neonates aged seven and fourteen days where the highest fecal SIgA levels $(2091.2 \mu \mathrm{g} / \mathrm{mL})$ were obtained in neonates aged fourteen who consumed breast milk only. This value is in accordance with research of Maruyama et al., 2009 which showed maximum SIgA levels in neonates who consumed breast milk in the first month was $4500 \mu \mathrm{g} / \mathrm{mL}$ and slightly higher than Hayati et al., 2016 research: 510-2040 $\mu \mathrm{g} / \mathrm{mL} .{ }^{13,14}$

This study findings that mean fecal SIgA levels in neonatal group aged fourteen who consumed breast milk only were significantly higher than aged seven days, this is in line with previous research. ${ }^{16,17}$ The mean of fecal SIgA levels in aged fourteen who consumed combination (breast milk and formula milk) and formula milk only were significantly lower than aged seven day, this can be explained that formula milk does not contain SIgA and neonates has not been able to produce SIgA until second week of life. While the fecal SIgA detected was thought to be produced by neonate himself through microbial factors and food antigens. ${ }^{13}$

Some treatments for neonates such as the administration of antibiotics or treatment in incubator can damage the colonization process. As previously explained, normal colonization with gastrointestinal microbiota was hypothesized to encourage the development of mucosal immune system including the production of plasmablast and gastrointestinal SIgA. ${ }^{18}$ Other research also found that broad spectrum antibiotics will disrupt immune system which inhibits bacterial colonization of intestinal tract and is able to reduce the colonization of commensal bacteria needed by gastrointestinal tract resulting in dysbiosis. ${ }^{19}$

Table 3. Paired sample t-test results of fecal Secretory immunoglobulin A, HBD-2, and Calprotectin of preterm neonates who consume breast milk only, breast milk and formula milk, and formula milk only on the seventh and fourteenth days

\begin{tabular}{|c|c|c|c|c|c|c|}
\hline \multirow[b]{2}{*}{ Day Observation } & \multicolumn{2}{|c|}{ Human breast milk only } & \multicolumn{2}{|c|}{ Human breast milk and formula milk } & \multicolumn{2}{|c|}{ Formula milk only } \\
\hline & $\begin{array}{c}\text { Mean }(\mathrm{SD})(\mu \mathrm{g} / \\
\mathrm{ml})\end{array}$ & p-value & $\begin{array}{c}\text { Mean (SD) } \\
\text { (ng/ml) }\end{array}$ & p-value & $\begin{array}{c}\text { Mean (SD) } \\
(\mathrm{ng} / \mathrm{ml})\end{array}$ & $p$-value \\
\hline \multicolumn{7}{|c|}{ Secretory Immunoglobulin A } \\
\hline Seventh & $1198,7 \pm 277,9$ & 0,01 & $1135,8 \pm 355,45$ & 0,01 & $733,17 \pm 248,94$ & 0,000 \\
\hline Fourteenth & $1541,9 \pm 418,6$ & & $826,29 \pm 311,5$ & & $387,66 \pm 162,39$ & \\
\hline \multicolumn{7}{|l|}{ HBD-2 } \\
\hline Seventh & $226,85 \pm 59,75$ & 0,039 & $308,81 \pm 39,96$ & 0,00 & $322,58 \pm 58,82$ & 0,015 \\
\hline Fourteenth & $204,47 \pm 40,63$ & & $351,66 \pm 38,18$ & & $375,73 \pm 68,12$ & \\
\hline \multicolumn{7}{|l|}{ Calprotectin } \\
\hline Seventh & $144,64 \pm 39,22$ & 0,021 & $189,97 \pm 64,92$ & 0,036 & $332,33 \pm 65,011$ & 0,021 \\
\hline Fourteenth & $119,97 \pm 38,94$ & & $299,1 \pm 139,38$ & & $441,41 \pm 173,48$ & \\
\hline
\end{tabular}

Note:p-value $<0,05=$ significant $\left.{ }^{*}\right)$ 
Table 4. Correlation of fecal SIgA, HBD-2, and calprotectin levels preterm neonates on the seventh and fourteenth days

\begin{tabular}{|c|c|c|c|c|c|c|}
\hline & \multicolumn{2}{|c|}{ SIgA } & \multicolumn{2}{|c|}{ HBD-2 } & \multicolumn{2}{|c|}{ Kalprotektin } \\
\hline & $r$ & p-value & $r$ & p-value & $r$ & p-value \\
\hline \multicolumn{7}{|l|}{ Seventh day } \\
\hline SIgA & - & - & $-0,467$ & 0,003 & $-0,456$ & 0,003 \\
\hline HBD-2 & $-0,467$ & 0,003 & - & - & $+0,466$ & 0,003 \\
\hline Calprotectin & $-0,456$ & 0,003 & $+0,466$ & 0,003 & - & - \\
\hline \multicolumn{7}{|c|}{ Fourteenth day } \\
\hline SIgA & - & - & $-0,789$ & 0,000 & $-0,805$ & 0,000 \\
\hline HBD-2 & $-0,789$ & 0,000 & - & - & $+0,769$ & 0,000 \\
\hline Calprotectin & $-0,805$ & 0,000 & $+0,769$ & 0,000 & - & - \\
\hline
\end{tabular}

Note: $p$-value $<0,05=$ significant ${ }^{*}$ )

In this study, $97 \%$ of subjects (38 samples) were treated with an incubator, $46 \%$ of subjects (18 samples) experienced respiratory problems and received antibiotics (15 neonates were born from premature ruptured of the membrane $<18$ hours) with the longest duration was 14 days. These factors are considered to affect fecal SIgA levels in all three groups.

The other fecal marker to detect GI inflammation is human beta defensin-2 (HBD-2). The lowest fecal level of HBD-2 in this research was 158.27 $\mathrm{ng} / \mathrm{mL}$, coming from a group aged fourteen days who consumed breast milk only. This value similar to previous study which described fecal HBD-2 level in healthy neonates aged 7 days was 30-470. ${ }^{20}$ Mean levels of fecal HBD-2 in the neonates group who consumed breast milk only was $215.65 \pm$ 51.34 which was significantly lower than neonates who consumed combination of breast milk and formula milk (330.24 \pm 44.08$)$, and formula milk only $(349,16 \pm 67.66)$. These results are consistent with preliminary research which showed fecal level of HBD-2 in breast milk only were much lower than those in the formula milk. The highest HBD2 levels were found in neonates aged fourteen days who consumed formula milk only which was 492 $\mathrm{ng} / \mathrm{mL} .{ }^{21}$ This value is higher than HBD-2 levels in healthy preterm neonates in study by Campeotto et al., 2010 which is $30-154 \mathrm{ng} / \mathrm{mL}$ and included in HBD-2 levels of neonates who experienced intestinal distress in the same study:2-1271 ng/mL. ${ }^{20}$ The highest fecal level of HBD-2 in this study was four times (5-1010 $\mathrm{ng} / \mathrm{mL}$ ) compared with Jenke et al., 2012 result. ${ }^{9}$ Levels of HBD-2 that stimulated from intestine are still low to achieve bactericidal effect in severe infections, in this case breast milk contributes to increasing HBD-2 levels. While the HBD-2 level in breast milk was $0.31-19.12 \mathrm{ng} / \mathrm{mL}$ for colostrum and $52.65-182.29 \mathrm{pg} / \mathrm{mL}$ for mature milk..$^{21,22}$
The average fecal level of HBD-2 in formula milk only showed no statistically significant difference with the average level in combination group, but significantly different compared to the breast milk only group. In line with Corebima's research, 2017 fecal level of HBD-2 in neonates who consumed formula milk whether using breast milk or not, did not show significant differences. Conversely, when compared with breast milk only group showed significant differences. This can be explained by a study conducted by Willems in 2015 that formula milk feeding can induce proinflammatory factors even though clinical signs of inflammation have not been found, whereas breast milk has a role in suppressing inflammation including in digestive tract. $^{21,23}$

This study also found that fecal levels of HBD2 from each sample group at the age of seven days and fourteen days had a mean difference that was statistically significant and correlated. In breast milk only group there was decrease in fecal HBD-2 levels on fourteenth day which was significantly different from seventh day. A previous publication described the fecal levels of HBD-2 of healthy preterm infants aged 14 days significantly decreased compared to the age of seven days and remained same until the 30th day. Decreased levels of fecal HBD-2 indicate reducing inflammatory reactions, especially in the infant's gastrointestinal tract. ${ }^{8}$ This is according to observations by Bering, 2018 in neonates aged 7 days who consume breast milk showed a reduced inflammatory reaction because breast milk able to protect gastrointestinal tract by stimulating immune system or providing substrate related to development of beneficial microbiota, especially in the first week of life. In line with research by Bhatia, 2013 breastfeeding only can reduce the incidence of gastrointestinal inflammation by $79 \%$, this value is significantly different when breastfeeding is combined with formula milk, both the composition of breast milk $>50 \%$ or $<50 \%$, which is only able to reduce $3.2-10 \%$ of gastrointestinal inflammation. Sisk et al., 2017 proves that gastrointestinal inflammation can decrease by six times in infants who consume breast milk in the first 14 days of life. ${ }^{24,25,26}$

However, there were two samples with higher fecal HBD-2 levels on the fourteenth day compared to the seventh day. This can be due to confounding factors that affect the outcome such as the possibility of bacterial growth when storing breast milk prior to neonatology. Previous research describes that contamination of breast milk can occur and cause morbidity in neonates. Samples using orogastrictube were also shown to have bacterial counts approaching $106 \mathrm{U} / \mathrm{mL}$ colonies. ${ }^{27}$ 
Giving a combination of breast milk and formula milk and formula milk only is statistically related to the average fecal level of HBD-2, on the fourteenth day with higher levels than the seventh day. Research conducted by Abram in 2014 showed formula feeding increased the incidence of inflammation by $15 \%$ and death by $8 \%$. Also described, every $10 \%$ increase in volume of formula milk will increases the risk of infection by $17.9 \%$. Increased fecal HBD-2 is associated with increased inflammatory response. As for some things that can improve the inflammatory response are respiratory distress, prolonged antibiotics, skin diseases, etc. ${ }^{28}$ In this study $46 \%$ of the samples (18 samples) in all groups experienced respiratory problems and received oxygen therapy using CPAP and 27 patients received antibiotics (15 neonates were born with premature ruptured of the membrane $<18$ hours) with the longest duration was 14 days. These factors are thought influencing the increase of fecal HBD-2 levels.

Another inflamatory marker that also can be easilly detected in fecal was calprotectin. The lowest fecal calprotectin in this study was $102.775 \mathrm{ng} / \mathrm{mL}$, originating from a group of preterm neonates who consumed breast milk only. This value is consistent with research conducted by Rugtveit and Fagerhol in 2002 which concluded that fecal calprotectin levels were found to be significantly lower in breastfed infants than infants who were formula-fed during the 'preweaning' period. However, there are some other researchers who have insignificant results, this is because neonatal samples in various age ranges and no information of pregnancy history or formula composition, which can affect levels of calprotectin..$^{29,30}$

This study proves that there are differences in fecal level of calprotectin from all groups that are statistically significant. Mean fecal calprotectin levels in the group that consumed breast milk only was $132.30 \pm 40.31 \mathrm{ng} / \mathrm{mL}$ were significantly lower than those who consumed a combination of breast milk and formula milk $(244.53 \pm 120.19 \mathrm{ng} / \mathrm{mL})$, and formula milk only $(386.87 \pm 139.89 \mathrm{ng} / \mathrm{mL})$. Although there are several studies that support the results of this study such as conducted by Asgarshirazi in 2017, but there are still other studies that have conflicting results, such as research conducted by Campeotto in in 2004. These findings may be caused by higher inflammation or a better immune response in breast-fed infants. ${ }^{20,31}$

Some factors can affect fecal level of calprotectin include gestational age, postnatal age, mode of delivery, antibiotic treatment, intestinal microbiota, and diet/nutrition. ${ }^{32}$ Research by Esmaeilizand in 2018 proves that giving antibiotics 5 days or more to preterm neonates without evidence of infection is associated with a significantly increased incidence of gastrointestinal infections. In fact, Arboleya in 2015 showed that the administration of prepartum antibiotics to pregnant women without evidence of premature rupture of the membranes or vaginal B group Streptococcus colonization can interfere with the growth of neonatal intestinal microbiota which further increases the risk of slow onset sepsis or necrotizing enterocolitis in neonates. ${ }^{33,34}$

Fecal calprotectin levels have been reported higher during the first few weeks of life in healthy full term (term) and preterm neonates than healthy adults or children, which shows that gastrointestinal mucosa in neonates is more likely to have an inflammatory process. ${ }^{20,35}$ Research conducted by Asgarshirazi in 2017 found that fecal calprotectin levels were higher in first month than sixth month which might be caused by immaturity of the intestinal barrier and excessive inflammatory response. In addition, Groer in his 2016 study stated that the presence of calprotectin in the feces of preterm and term infants is an indication of gastrointestinal microbiota maturation, because neutrophils migrate to the digestive tract due to the process of developing microbial colonization. Protection against pathogenic microbes occurs when commensal microbiota develops. ${ }^{31,36}$ Oral supplementation by Bifidobacterium lactis $\mathrm{Bb} 12$ modifies the balance of the gastrointestinal microbiota causing a significant reduction in calprotectin levels in probiotic group compared to placebo ${ }^{37}$ High fecal calprotectin levels in newborns show increased granulocytes in gastrointestinal lumen due to an increase in gastrointestinal permeability and/or the development of lymphoid tissue associated with gastrointestinal tract. ${ }^{30}$

Based on the correlation test, increase fecal SIgA levels was followed by decrease in fecal HBD-2 and calprotectin level. Subjects with the highest fecal SIgA levels $(2091.2 \mu \mathrm{g} / \mathrm{mL})$ having fecal HBD-2 levels of $154 \mathrm{ng} / \mathrm{mL}$ and calprotectin 114,025 ng/ $\mathrm{mL}$, while subjects in the same group with SIgA levels of $835.8 \mu \mathrm{g} / \mathrm{mL}$, has higher fecal HBD-2 levels of $184 \mathrm{ng} / \mathrm{mL}$ and calprotectin $200,525 \mathrm{ng} / \mathrm{mL}$. Meanwhile, fecal levels of HBD-2 and calprotectin have an equal correlation, which means that high calprotectin level are synergized with increased fecal HBD-2 level, although it cannot be determined whether they are mutually influential or only one that induces the other. This can be observed in samples with highest fecal calprotection level of $777.75 \mathrm{ng} / \mathrm{mL}$ having a fecal HBD-2 level of $403 \mathrm{ng} /$ $\mathrm{mL}$, while subjects in the same group with a fecal level of calprotectin $737,275 \mathrm{ng} / \mathrm{mL}$ have HBD-2 fecal level of $311 \mathrm{ng} / \mathrm{mL}$. 
Based on clinical conditions, two neonates who consumed breast milk only did not show gastrointestinal symptoms while 11 other neonates were found with clinical symptoms of vomiting or enlarged abdomen, or both. Subjects with highest fecal SIgA levels still experienced vomiting and enlarged abdomen with fecal HBD-2 level was $154 \mathrm{ng} / \mathrm{mL}$ (not the lowest level in the study) and fecal calprotectin level was $114,025 \mathrm{ng} / \mathrm{mL}$ (which was also not the lowest level). This condition can be explained by Gopalakrishna et al., 2019 that the level of SIgA detected in feces does not reflect the ability of these components to bind with pathogenic bacteria where neonates with gastrointestinal inflammation have low IgA binding with bacteria. Things that affect the quality of SIgA in neonates besides breastfeeding and the quality of maternal SIgA, was aturity of gastrointestinal immunity which actually will develop with age. ${ }^{12}$

There are several limitations in this study; (1) samples obtained by consecutive sampling with limited research time; (2) there are still confounding factors that are difficult to avoid and can affect the results; (3) measurement of fecal parameters is only done twice (age seven days and fourteen days), so the exact pattern of change cannot be known; (4) does not measure marker levels in meconeum; (5) anti-inflammatory mechanism is also played by other anti-inflammatory cytokines that are induced, so that it can influence the level of proinflammatory markers (HBD-2 and calprotectin).

\section{FUNDING}

None

\section{CONFLICT OF INTEREST}

No Conflict of Interest

\section{REFFERENCE}

1. Baricelli J, Rocafull MA, Vázquez D, Bastidas B, BáezRamirez E, Thomas LE. 2015. Beta-defensin-2 in breast milk displays a broad antimicrobial activity against pathogenic bacteria. J Pediatr (Rio J); 91:36-43.

2. World Health Organization. 2020. Neonatal Mortality 2020: WHO

3. Utomo, MT. 2010. Neonatal sepsis in Low Birth Weight Infants in Dr. Soetomo General Hospital. Indonesian Journal of Tropical and Infectious Disease; 1: 86-89.

4. Neu J, Walker WA. 2011. Necrotizing Enterocolitis. New England Journal Of Medicine; 364: 255-264.

5. Juniarto R, Kadim M. 2014. Faktor Risiko yang Memengaruhi Kolonisasi Mikroflora Saluran Cerna Neonatus Kurang Bulan dengan Enterokolitis Nekrotikans. Sari Pediatrica; 15(6): 353-360.

6. Hanson LA, Korotkova M. 2012. The Role of Breastfeeding in Prevention of Neonatal Infection. 7: 275-281.

7. Avula S, Smith LN, Monga R, Lockwood L, Kadrofske M. 2017. Stool Biomarkers to Diagnose Necrotizing
Enterocolitis in Preterm Infants: A Pilot Case-Control Study. Pediatrics; 140(1):1-7.

8. Campeotto F, Baldassarre M, Laforgia N, Viallon V, Kalach N, Amati L, Butel MJ, Dupont C, Kapel N. 2010. Fecal Expression of Human Beta Defensin 2 following Birth. Neonatology; 98:365-369.

9. Jenke AC, Zilbauer M, Postberg J, Wirth S. 2012. Humandefensin 2 expression in ELBW infants with severe necrotizing enterocolitis. Pediatr Res;72:513-20.

10. Good M, Sodhi C. P, Hackam D.J. 2014. Evidence-Based Feeding Strategies Before And After The Development Of Necrotizing Enterocolitis. Expert Review Of Clinical Immunology; 2: 1-10.

11. Mantis NJ, Rol N, Cothersy B. 2011. Secretory IgA's Complex Roles in Immunity and Mucosal Homeostasis in the Gut. Mucosal Immunol; 4(6): 603-611.

12. Retnaningtyas LP, Etika R, Sudarmo SM. 2010. Effectof Probiotic Administration on The Levels of Fecal Secretory Immunoglobulin A in Preterm Infants. Folia Medica Indonesiana; 46(1): 15-23.

13. Bridgman SL, Konya T, Azad MB, Sears MR, Becker AB, Turvey SE, Mandhane PJ, Subbarao P, Scott JA, Field CJ, Kozyrskyj. 2016. Infant Gut Immunity: a Preliminary Study of IgA Association with Breastfeeding. Journal of Development Origin of Health and Disease; 7(1): 68-72.

14. Hayati N, Kadim M, Mangunatmadja I, Soedibyo S, Ifran EB, Sjakti HA. 2016. Gut wall integrity in exclusively breastfed vs formula fed infants. Paediatr Indones; 56(4): 199-204.

15. Kuitunen M, Savilahti E. 2015. Mucosal IgA, mucosal cow's milk antibodies, serum cow's milk antibodies and gastrointestinal permeability in infant. Pediatr Allergy Immunol; 6: 30-35.

16. Maruyama K, Hida M, Kohgo T, Fukunaga Y. 2009. Changes in salivary and faecal secretory IgA in infants under different feeding regimens. Pediatrics International; 51: 342-345.

17. Scholtens PAMJ, Alliet P, Raes M, Alles MS, Kroes H, Boehm G, Knippels LMJ, Knol J, Vandenplas Y. 2008. Fecal Secretory Immunoglobulin A is Increased in Healthy Infants Who Receive a Formula with Short-Chain GalactoOligosaccharides and Long Cahin Fructo-Oligossacharides. The Journal of Nutrition; 138(6): 1141-1147.

18. Retnaningtyas LP, Etika R, Sudarmo SM. 2008. Effectof Probiotic Administration on The Levels of Fecal Secretory Immunoglobulin A in Preterm Infants. Folia Medica Indonesiana; 46(1): 15-23.

19. Tanner SM, Beryhill Ellenburg JL, Jilling T, Cleveland DS, Lorenz RG, Martin CA. 2015. Pathogenesis of Necrotizing Enterocolitis: Modeling the Innate Immune Response. The American Journal of Pathology; 185(1):1-13.

20. Campeotto F, Butel MJ, Kalach N, Derrieux S, AubertJacquin C, Barbot L. 2004. High fecal kalprotektin concentrations in newborn infants. Arch Dis Child Fetal Neonatal Ed; 89(4):F353-F355.

21. Corebima B. 2017. Kadar Human Beta Defensin dalam tinja dan pola mikrobiota saluran cerna pada neonatus kurang bulan yang mendapat ASI, susu formula, maupun kombinasi. [Disertasi]. Fakultas Kedokteran Universitas Indonesia: Jakarta.

22. Rousias JG, Karagounis P, Parvulesku G, Legakis NJ, Tsakris A. 2010. In Vitro Bactericidal Activity of Human Beta Defensin 2 againts Nosocomial Strain. J.peptide; 31: 1654-1660.

23. Willems R, Rybicki V, Jiang P, Sangild PT, Shen RL, Hensel KO, Wirth S, Postberg J, Jenke AC. 2015. Introduction of formula feeding induces structure in the intestine of preterm pigs. Mol cell pediatr; 2(1): A6.

24. Bering SB. 2018. Human Milk Oligosaccharides to Prevent 
Gut Disfunction and Necrotizing Enterocolitis in Preterm Neonates. Nutrients; 10(10): 1461.

25. Bhatia J. 2013. Human milk and the prematur infant. Ann Nutr Metab; 62 (3): 8-14.

26. Sisk PM, Lovelady CA, Dillard RG, Gruber KJ, O'shea TM. 2017. Early human milk feeding is associated with a lower risk of necrotizing enterocolitis in very low birth weight infants. Journal of perinatology; 27: 428-433.

27. Levebvre F, 1990. Breast Feeding Among Mother of Low Birth Weight Infants. 1990. Can Fam Physician; 36: 15331536.

28. Abram SA, Schanler RJ, Lee ML, Recthman DJ. 2014. Greater mortality and morbidity in extremely preterm infant fed a diet containing cow milk protein products. Breastfeeding medicine; 9(6): 281-285.

29. Rugtveit J, Fagerhol MK. 2002. Age-dependent variations in fecal kalprotektin concentrations in children. J Pediatr Gastroenterol Nutr; 34(3):323-324.

30. Kapel N, Campeotto F, Kalach N. 2010. Fecal kalprotektin in term and preterm babys. Journal of Gastroenterology Hepatology and Nutrition; 51(5): 542 - 547.

31. Asgarshirazi M, Shariat M, Nayeri F, Dalili H, Abdollahi A. 2017. Comparison of Fecal Clprotectin in Exclusively Breastfed and formula or Mixed Fed Infants in the First Six Months of Life. Acta Med Iran; 5(1): 1-5.

32. Baldassarre ME, Altomare MA, Fanelli M. (2007). Does kalprotektin represent a regulatory factor in host defense or a drug target in inflammatory disease? Endocr Metab Immune Disord Drug Targets; 7(1): 1-5(5).
33. Esmaeilizand R, Shah PS, Seshia M, Yee W, Yoon EW, Dow K. 2018. Antibiotic Exposure and Development of Necrotizing Enterocolitis in Very Preterm Neonates. Paediatrics \& Child Health; 23(4): e56-e61.

34. Arboleya S, Sánchez B, Milani C, Duranti S, Solís G, Fernández $\mathrm{N}$, Gavilan $\mathrm{R}$, Ventura $\mathrm{M}$, Margolles $\mathrm{A}$, Gueimonde, M. 2015. Intestinal Microbiota Development in Preterm Neonates and Effect of Perinatal Antibiotics. The Journal of Pediatrics; 166(3): 538-544.

35. Vaos G, Kostakis ID, Zavras N, Chatzemichael A. 2013. The role of kalprotektin in pediatric disease. Biomed Res Int; 2013:542363

36. Groer M, Ashmeade T, Louis-Jacques A, Beckstead J, Ji M. 2016. Relationships of Feeding and Mother's Own Milk with Fecal Kalprotektin Levels in Preterm Infants. Breastfeeding Medicine, 11(4).

37. Mohan R, Koebnick C, Schildt J, Mueller M, Radke M, Blaut M. 2008. Effects of Bifidobacterium lactis Bb12 supplementation on body weight, fecal $\mathrm{p} \mathrm{H}$, acetate, lactate, kalprotektin, and Ig A in preterm infants. Pediatr Res; 64(4):418-422.

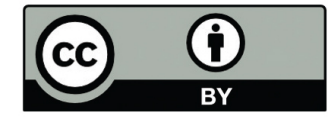

This work is licensed under a Creative Commons Attribution 